\title{
Business Motives among Students: A Qualitative Appraisal of Drive Theory
}

\author{
Laraib Tareen $^{1}$, Fowzia Noor Mengal ${ }^{2}$, Nadeem-Uz-Zaman*3, Manzoor Ali Brohi ${ }^{4}$ \\ \& Hadi Hassan Khan ${ }^{5}$ \\ 1,2,3,4,5 Balochistan University of Information Technology, Engineering and Management Sciences, Quetta, \\ Pakistan
}

\begin{abstract}
The main purpose of conducting this exploratory qualitative research was to determine the nature of drive theory among business students, where drive is a motivation for some behavior based on a biological need. The target population of our study was the universitylevel business students. We used the existing literature on drive theory for the development of interview protocol. After the finalization of the interview protocol, six semi-structured interviews were conducted with the business students enrolled in different programs with different fields of specialization. The data were analyzed using ATLAS.ti version 8 . We found that business-related motivation was created by six drivers including aggressiveness, acquisition, achievement, social recognition, personal goals and desire for power.
\end{abstract}

Key words: Business students, Qualitative Research, Drive Theory

\section{Introduction}

Researchers of the field suggest that the individuals behavior is always guided by specific drives or emotional needs, which are usually the consequence of our evolutionary inheritance (Nohria et al., 2008). The drive theory maintains that individuals are motivated to perform specific actions to minimize the internal stress as a consequence of unfulfilled bodily needs. This theory is beneficial in comprehending only such behavior that contains a substantial biological element, such as physical needs and desires. Thus the motivation of individuals in the face of a physical need may be termed as a drive.

Individual behavior can also be explained through a drive, habit, and a set of other factors as well as incentives (Hull, 1943; Spence, 1956). That is, an individuals motivation towards the execution of particular behavior is dependent on the extent of bodily requirements multiplied by the intensity of appropriate patterns of behavior backed up by certain rewards (Weiner, 2010). Additionally, Lawrence and Nohria (2002) claimed that nature of an individual plays a significant role in shaping the choices they make in their everyday life. The researcher argued that the human drives to comprehend, bond, defend, and acquire.

* Corresponding author.

Email: naz_e_zeest@yahoo.com 
Motivation is defined as a driving force behind an individuals actions of all types (Rabideau, 2005). Drive refers to stimulation that arises from within the organism on the frontier between the mental and the somatic ... a measure of the demand made upon the mind for work in consequence of its connection with the body(Freud, 1957). Several researchers contributed to the drive theory differently. Drives were conceived in evolutionary circumstances (Freud, 1957, 2021). Freud (1920) suggested the presence of aggression and libido drives originating from fundamental biological instincts of death and love.

The disciplines of sociology, psychology, decision making and economics all together hold a common aspiration to understand the fundamental disposition, character, or temperament of human nature. Such an enormous consideration of multidisciplinary attention towards the determination of who we are indicates the tremendous consequences of this endeavor (Steel and König, 2006). Luckily, the latest cross-disciplinary researches in domains like biology, neuroscience, evolutionary psychology have also enabled us to discover more about the human brain (Nohria et al., 2008).

The issue with drive theory is that the behavior of an individual is not always stimulated by physiological needs only. For example, people can also eat when usually they are not even really hungry (Ondabu, 2014). Motivation, attitudes, and intentions are discussed quite extensively in the existing literature; however, very little attention has ever been paid to the applicability of drive theory to business world (De Jorge-Moreno et al., 2012). Despite the fact that some studies have tried to explore the connections of drive theory in business fields; for example, the motivation of women to start businesses in developed and emerging economies (Solesvik et al., 2019) and examining the role of culture on the motivational behaviors of women entrepreneurs in Mongolia (Aramand, 2013). Jones and Paulhus (2011) claim that exploration of attitudes and motivation towards entrepreneurship among students is yet to be explored area with regards to understanding the nature of drive theory.

Furthermore, researches were also conducted to investigate the entrepreneurial orientations, entrepreneurial intentions, and entrepreneurial desires of business students (Elenurm, 2012; Gelaidan and Abdullateef, 2017; Palalić et al., 2017), experiences of business graduates while seeking admission in offshore MBA programs and how these MBA programs had met their needs (Ly et al., 2015), different factors determining the intentions of the student to study at universities (Watjatrakul, 2014) and new theory on incubation business was also developed using the social mechanisms approach (Ahmad, 2014).

Genoveva and Kartawaria (2020) found the factor that most influenced the business orientation is culture. Ran and Shi (2020) discovered that business students have a strong sense of opportunities and can grasp them and they may also choose to commence a business because of the temptation of resources and situations as compared to students from other majors. Attitude to sustainable development is more favorable among business students as compared to the nationwide sample. Soomro et al. (2020) found a positive and significant impact of Perceived feasibility, Perceived Desirability, and self-efficacy on Entrepreneurial intention among business students of Pakistani universities.

Bask et al. (2020) found that business students got higher scores on openness to change and self-enhancement, and lower scores on self-transcendence and conservation. Also, Jena (2020) examined the impact of attitude towards entrepreneurship education on entrepreneurial intention. Mahendra et al. (2017) found no direct relationship between entrepreneurial education and entrepreneurial intention among students of faculty of Management, Faculty of Economics. Entrepreneurial education takes part as an antecedent variable that contributes to affect directly on both entrepreneurial attitude and entrepreneurial motivation, and its impact indirectly on 
entrepreneurial intention.

Review of the literature suggests that no such research was conducted on determining the driving forces that motivated the students throughout their business program. Therefore, the purpose of this study is to determine the nature of the drive theory of motivation in business students in Pakistan, specifically in the context of Baluchistan. In other words, the basic objective of the current study is to explore substantial factors, other than physiological factors, that functioned as a driver or motivator for business students, which enabled them to remain committed and paved their path towards the achievement of academic excellence in the business program.

\section{Methodology}

This study aimed at conducting narrative qualitative research to determine the nature of drive theory among business students by using the semi-structured interview method. We tried to narrate the nature of drive theory with the perspective of business students only. The target population for this study was the university-going business students. Overall six interviews were conducted from business students enrolled in different programs with different fields of specialization.

\subsection{Interviewees}

According to the purpose of the current study, the target population was business students with the sample size of total six business students, as it is sufficient to conduct in-depth interviews from the participants within in the range of 5 to 50 for qualitative study (Dworkin, 2012). Later, by means of convenience sampling method, we conducted six interviews of business students enrolled in different programs with different fields of specialization areas at Balochis$\tan$ University of Information Technology, Engineering and Management Sciences (BUITEMS). Overall, six interviews were conducted with 3 boys and 3 girls to maintain balance among gender opinions as well. We tried to take interviews from senior students like MBA and MS students because they have more experience regarding different motives, to get primary information on the subject under study. The participants were enrolled in MS, BS, and MBA with different areas of specialization.

\subsection{Instrument}

The authors developed an interview protocol to collect data from business students. The interview protocol was developed in accordance to the basic drives of an individual which has previously been studied in literature. The researchers also highlighted some probes in our interview protocol to get further information about the participant. They conducted tape recording interviews and transcribed them into ATLAS. Ti 8 and ended up creating six major categories. The above-mentioned software assisted the researchers in the process of coding, creating categories, and finally converting categories into a major theme.

\subsection{Interviews and Transcription}

We conducted face-to-face interviews, where we as interviewers introduced ourselves, research purpose, its objectives, and its importance. Participants were ensured that their data will 
be kept confidential as per the demand of each interviewee. Participants were inquired with several questions relative to drive theory systematically in the reasonable length of minimum 25 minutes of lengths. Further, it was ensured that the collection of data must be relevant to drive theory by reviewing literature as well. Finally, the researchers converted interviews into transcription then sent the file into ATLAS Ti 8.

\subsection{Analysis}

ATLAS Ti 8 software was used for the generation of different types of categories for current study. Firstly, the authors transcribed all the interviews that were conducted through the utilization of semi-structured interview protocol and recorded at minimum time duration of 25 minutes. Later, thorough reading and re-reading of the transcribed semi-structured interviews resulted in the development of different networks with various themes and further in the formation of six major categories. Following were the six major identified categories of the current qualitative research:

1. Acquisition motives

2. Achievement motives

3. Power Motives

4. Passion motives

5. Personal motives

6. Social motives

\section{Results and discussions}

The majorly identified categories of our study are discussed in the following section:

\subsection{Acquisition Motives}

Most of the business students took secured admission in the relative business program for acquiring a business degree and later the utilization of this business degree in the successful implementation of their business startup and for seeking a job in the corporate sector. A student reported, I want to seek a job in the corporate sector that would lead towards the enhancement of my marketing skills as well. Another stated,

I will utilize my degree for seeking a particular job and if I do not get the opportunity of doing a job then I will prefer to open my own business. I want to utilize the skills that I have attained in this program to its fullest. Concerning the scope of the business program, most of the students took admission in the business program for acquiring employment opportunities with highly attractive salary packages due to its rising scope in the market, skills, and abilities required for the implementation of their business idea and unique identity in this society. Our claim was supported by a student by saying, I would prefer to select the job that is offering me a highly attractive salary because I do not think that I will be satisfied with selecting the mediocre level of job with an average salary. 
Others wanted to contribute to society and get the opportunity of utilizing their inborn personality traits in this field, which was otherwise not possible in other fields of study. A student reported,

I will utilize this degree to seek a job as well to open a business of my own. I would like to become a lecturer because I think it is the best way to contribute to this society. I am also planning to execute my own business in a standardized economy.

\subsection{Achievement Motives}

Students enrolled in the business program also worked hard towards the achievement of something better for their self-satisfaction in the program.

I want to perform better for my satisfaction. I feel bad about scoring less in exams. I do not prefer to study more or to stay awake until late nights or even my parents do not pressurize me for getting good grades but when I fail to achieve good grades then I feel bad when I do not get for what I studied.

Most of the business students worked effortlessly to achieve higher grades, while others worked towards the attainment of their CGPA within the specific range of not going below 3CGPA or above 3.5 CGPA. Another interviewee showed her concern by saying,

My cravings for achieving good grades never ends specifically when once you achieve something bigger than you work more towards its attainment for time and again. Sometimes when I fail to attain the desired results then I work harder to rectify my mistakes for next time.

These business students were also involved in the gradual acceptance of challenging tasks to outperform others. They also preferred to take feedbacks from their concerned teachers to achieve perfection in their work with rectifying their mistakes leading towards the achievement of relevant skills and continuous improvement. A student stated, I take feedbacks from my concerned teachers and friends for the rectification of my mistakes and to seek appreciation from them regarding my work. Another mention,

I appreciate taking feedbacks regarding the performance of my tasks. I feel bad in situations when the teacher does not give me any feedback after the deliverance of my presentation as well because I want to know that what were the mistakes that I committed and how can I rectify my mistakes. Therefore, for me, feedback matters a lot to know where I am standing.

They also preferred to take seek assistance from their family in making major decisions of their life more specifically in selecting the particular field of study.

\subsection{Power Motives}

Business students also exhibited the need for the attainment of power in relative group assignments, projects, tasks, and in seeking any employment opportunity as well. One student backed up this finding by saying, I want to perform as a group leader because I want people to follow me not that I am going to follow people. Another interviewee also quoted, Yes, attainment of power is very necessary to influence others in every sphere of life. Most of these students preferred to perform the role of a leader in the execution of particular group tasks. These students were quite successful in attaining power motives, as they were also performing the role of group leaders of their final case study project and research project as well. They were also involved in the execution of effective leadership styles and the management of conflicts such as the creation of a friendly environment and distribution of work according to the competency of their group members. 
In terms of seeking employment opportunities, some wanted to apply for a mediocre level of job to get the basic level of understanding regarding the execution of the particular job and later to utilize this practical knowledge for performing higher-level jobs effectively. One of the students supported our claim by saying,

I think I will start with mediocre job rank first. I would like to first attain a basic level of understanding from lower ranks job then only I would be able to perform in a higher executivelevel job.

However, some students wanted to initiate business individually while others wanted to initiate business in partnership with their friends that will eventually result in the creation of diverse business expertise and synergy among the group.

\subsection{Passion Motives}

Business students were usually faced with pressure and stress regarding their coursework. Their main motive was to transform their failure into their success. They felt the burden of assignments, quizzes, and projects and they are efficiently involved in coping up with such situations. When they felt stress first they tried to relax for a couple of hours and seek peer support. As one of our interviewees expressed, "I prefer to stay in the company of my friends to cope up with stress rather than stay in isolation.

They tended not to give-up and tried to self-control them that they can get done their projects and assignments on time. One of our interviewees supported this claim of ours: However, if that stressful situation has occurred due to delayed work then I try my best to complete that task first even if I had to make sacrifices I will go for it. They were also involved in following effective stress management practices through physical and mental exercises. Some of the business students seek motivation through changing their stressful environment by doing drawings, coloring, and listening to music as well.

I have researched a lot on overcoming the stress and anxiety in life. I succeeded at determining the solution for relieving stress by doing both physical and mental exercises. I usually follow the technique of doing drawings, coloring my notes, work on changing environment, do excessive walk, seek help through music and acquiring 20 minutes sleep in between any tasks relieve my stress and anxiety.

\subsection{Personal Motives}

Business students were inclined to consider personal motives towards the achievement of their goals. One of the interviewees stated,

My habits are studying or giving time to family and learning business in spare time which will help me in achieving goals. I love to spend time in the library but I don't have enough time for it so I have made up a library for myself at home.

Most of the students developed time management, consistency habits, excessive reading habits, and searching for new information that helps them to accomplish their goals. Whereas, there are some obstacles like societal influence, family conflicts, and participation barriers, which hindered students to achieve their goals but most of the students were motivated enough to handle such barriers with the help of time management and consistency habits. A student reported,

Other than this family conflicts influence in achieving goals because I have to give time to family, job, and learning of business so it's tough for me to give time each of them so for all this 
one needs to do time management. If you do time management then you have control over the conflicts, and I try to solve family conflicts but somehow these factors affect my goals.

The existence of negative societal influence resulted in the de-motivation of some girls but in response, girls were quite motivated to achieve their goals and they did not want to sacrifice their performance level. One interviewee stated that she wants to achieve her goals and help her parents not to make them feel the necessity of having a son. This claim was supported by one of the female students who reported,

There are some societal pressures which might influence my productivity but I do not let them affect my studies. Being a family with no brother to earn, pricks me sometimes but this factor also motivates me to do something big so that my family would not feel the necessity of having a son to serve them.

\subsection{Social Motives}

Along with the attainment of academic excellence, some business students also emphasized the fulfillment of social motives such that they tried to get themselves more involved in social and co-curricular activities arranged by the university. Their indulgence in social activities and co-curricular activities enabled them to develop links with other resourceful individuals. As one interviewee stated,

I prefer to participate in social or group activities conducted by the university because one should not limit himself/herself to studying few books only. One should seek to interact with people then their skills would be polished and developed and they can gain relevant experience as well.

The development of excessive social interactions also strengthened their choices of giving more importance to human relations. Most of the students also avoided switching groups for the attainment of both monetary and non-monetary benefits. They preferred to stay with their group and help them in maximization of resources through teamwork. One of our interviewee compiled

I will prefer to stay with the familiar group with least resources and expertise because you can work better with the individuals you know and in a familiar group people know each other skills and competency level which is a quite potential thing to do and through teamwork, even the scarce resources can be utilized to its fullest. Yet another stated,

Whenever shifting is concerned for attaining something more beneficial so I would definitely go for selecting the group with maximum resources but if it is about maintaining my relationships then I will not switch groups and its unethical as well. I will give more priority to humans rather than monetary benefits.

\section{Discussion and Conceptual Framework}

Based on our results and the review of existing literature we argue that the motives highlighted as the business-learning drivers can be associated in a more meaningful manner (Casciaro, 1998). Starting our discussion from the personal and social motives, we suggest that the personal motives depend upon the social motives of the students as it is the society that shapes personal inclinations. Growing up in the society, people have certain social motives like affiliation, aggression, altruism, comfort and approval, which could work as driving force for activation of personal motives (Casciaro, 1998). The personal motives lead person in certain way to act 
in different pattern based on the influence taken from social motives (Sears, 1951). The object of getting something desirable like incentives, reward, success, and encouragement are considered best examples of personal motives triggered by social motives. The personal motives generally result in development of sense of acquisition within society that could build up aggression motives and lead the people in particular direction. People have strong acquisition motives that could only be possible to achieve through passion or aggression motives (Sears, 1951; Specht et al., 2014). Notwithstanding, we propose that students personal motives are embedded in their social motives.

The common examples of acquisition motives could be earning wealth, capture strong social position, successful personality and looking unique in the society (Carlson and McChesney, 2015; Michalos, 2008). In other ways, it can be said acquisition motives lead to certain satisfaction level by achieving power, position and other desirable objects in the society (Specht et al., 2014). In class-based society, people have high degree to power motives that could satisfy their achievement motives but through taking basic input from social, personal, aggression and acquisition motives. We argue that students get motivated by the acquisition of high wealth and income that can make them better-off in the society (Davies et al., 1995; Helmreich et al., 1978; Kerckhoff, 1976; Michalos, 2008; Wilson, 1997). Therefore, we suggest that acquisition motives are outcomes of the personal motives of students. Thus, we propose a relationship between personal and acquisition motive such that former determines the latter.

Talking about personal values in the society, people can form instrumental and terminal values to move towards achievement motives (Sears, 1951; Specht et al., 2014; Thorne, 2000). Hence, it could be elaborated through the scientific discussion that social motive, personal motives, aggression motives, acquisition motives and power motives are considered as instrumental values those could lead person towards achievement of power (Balon et al., 2013; Busch et al., 2013; Maqsud, 1980; Obschonka et al., 2019; Vallerand et al., 2003). In other words, power is not independent of societal motives, personal yearning, and actual achievement (Davies et al., 1995; Ho and Astakhova, 2020; Kerckhoff, 1976; Vallerand et al., 2003). Hence, the determination of achievement motive depends on all factors that reside in the society, in personal motives and in the motive of achievement (Sears, 1951). We, therefore, place the power motives in our conceptual model as being determined through all those factors.

We put the achievement motive of business student as an outcome of acquisition motive. Since achievement cannot take place without acquisition (Davies et al., 1995; Kerckhoff, 1976; Wilson, 1997). So, we argue that when students motive to achieve is driven by acquisition. Students are driven by achievement motive once they have already reached the acquisition level since no achievement is possible without acquisition (Carlson and McChesney, 2015; Helmreich et al., 1978; Michalos, 2008). It is this reason; we have put the achievement motive as an outcome of the acquisition motive. Considering this discussion, we propose the following conceptual framework as given in figure 1 :

\section{Conclusion}

In the review of drive theory literature, it was observed that our understanding of drive theory demanded further development due to the basic presumptions-associated limitations of previous theoretical frameworks. The issue with drive theory is that the behavior of an individual is not always stimulated by physiological needs only. Moreover, motivation, attitudes, and intentions are discussed quite extensively in the existing literature; however, very little attention 


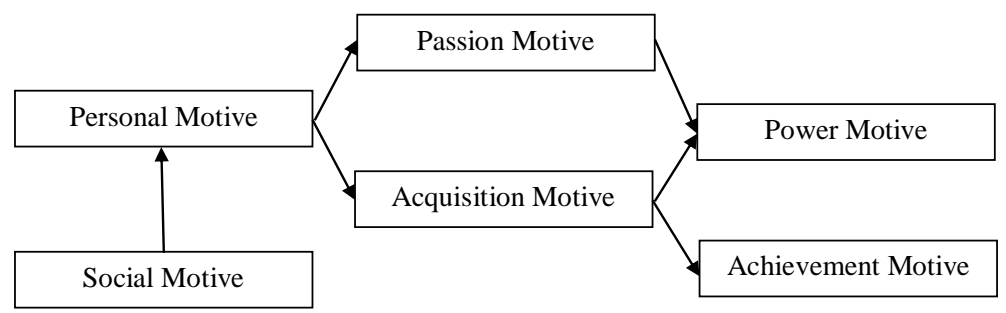

Figure 1: Conceptual Framework of the Themes

has ever been paid to the applicability of drive theory to business world. There is a need to explore the factors affecting students intentions for becoming entrepreneurs. The need for and impact of entrepreneurial education in Pakistan still needs to be explored. The current study is an effort to know the motives of business students of Pakistan.

The process of entrepreneur includes an examination of behavioral role and situational factors (Gartner, 1985) and demographic variables (Davidsson, 1995) on the intentions to commence a new business startup. These variables help to advance entrepreneurial drive among the students who want new startup. Current business students are future business leaders, and it is essential to study and examine their entrepreneurial drive and refine their entrepreneurial profile. Therefore, current study has contributed to existing literature of drive theory by exploring the psychological drives of business students of Pakistan.

The findings of the current study can have implications for the formulation of policies and strategies for encouraging business students in opening up their own businesses. Moreover, the results will also encourage the higher authorities of universities in determining different motivational factors that enabled business students to secure admission in the business program and the extent to which they strive to fulfill their motives by indulging in different activities to achieve their goals. It will also enable researchers to explore more on the psychological drives of an individuals rather than focusing on physiological drives only.

The results revealed that most of the business students took admission in the business program for accomplishing their acquisition motives of getting the business degree and successful utilization of this degree in acquiring employment opportunities and acquired business knowledge in starting their businesses. Others wanted to acquire the opportunity of utilizing their inborn personality traits in the business field due to its rising scope in the market which was otherwise not possible in other fields of study. They were also inclined towards the accomplishment of achievement motives as well by working effortlessly to obtain the desired CGPA according to their competency and urged towards participating in challenging tasks for their self-satisfaction. They also preferred to seek feedback and suggestions from concerned teachers and parents to seek perfection in their academics.

Business students revealed their inclination towards the attainment of power motives in relative group projects, assignments, tasks, and jobs as well. They successfully satisfied their need to attain power by volunteering as a group leader in particular group assignments and applied for jobs that enabled them to gain maximum benefits in terms of acquiring both monetary and non-monetary resources.

These students also exhibited the motives of transforming their failures into success. They did not let their personal and academic life failures affect their goals of achieving something bigger in this program. They also developed certain productive habits and practices for achieving 
personal motives of accomplishing their academic goals. Along with the goals of attaining excellence in studies, these students also emphasized the accomplishment of social motives in their academic life by participating excessively in social events and co-curricular activities arranged by the university.

\section{References}

Ahmad, A. J. (2014). A mechanisms-driven theory of business incubation. International Journal of Entrepreneurial Behavior \& Research.

Aramand, M. (2013). Women entrepreneurship in mongolia: the role of culture on entrepreneurial motivation. Equality, Diversity and Inclusion: An International Journal.

Balon, S., Lecoq, J., and Rimé, B. (2013). Passion and personality: Is passionate behaviour a function of personality? European Review of Applied Psychology, 63(1):59-65.

Bask, A., Halme, M., Kallio, M., and Kuula, M. (2020). Business students value priorities and attitudes towards sustainable development. Journal of Cleaner Production, 264:121711.

Busch, H., Hofer, J., Chasiotis, A., and Campos, D. (2013). The achievement flow motive as an element of the autotelic personality: Predicting educational attainment in three cultures. European journal of psychology of education, 28(2):239-254.

Carlson, R. and McChesney, C. (2015). Income sustainability through educational attainment. The Exchange, 4(1).

Casciaro, T. (1998). Seeing things clearly: Social structure, personality, and accuracy in social network perception. Social Networks, 20(4):331-351.

Davidsson, P. (1995). Determinants of entrepreneurial intentions. In RENT XI Workshop.

Davies, B., Apple, M. W., Close-Thomas, F., Wexler, P., Halliday, M., Danzig, A., Hasan, R., and Illera, J. L. (1995). Knowledge and pedagogy: The sociology of Basil Bernstein. Greenwood Publishing Group.

De Jorge-Moreno, J., Castillo, L. L., and Triguero, M. S. (2012). The effect of business and economics education programs on students' entrepreneurial intention. European Journal of Training and Development.
Dworkin, S. L. (2012). Sample size policy for qualitative studies using in-depth interviews.

Elenurm, T. (2012). Entrepreneurial orientations of business students and entrepreneurs. Baltic Journal of Management.

Freud, S. (1920). Beyond the pleasure principle. SE, 18:7-66.

Freud, S. (1957). Instincts and their vicissitudes. In The Standard Edition of the Complete Psychological Works of Sigmund Freud, Volume XIV (1914-1916): On the History of the Psycho-Analytic Movement, Papers on Metapsychology and Other Works, pages 109-140.

Freud, S. (2021). Three essays on the theory of sexuality. eBookIt. com.

Gartner, W. B. (1985). A conceptual framework for describing the phenomenon of new venture creation. Academy of management review, 10(4):696706.

Gelaidan, H. M. and Abdullateef, A. O. (2017). Entrepreneurial intentions of business students in malaysia: The role of self-confidence, educational and relation support. Journal of Small Business and Enterprise Development.

Genoveva, G. and Kartawaria, F. N. (2020). Asian and african business students: A comparative analysis of their motivation, family support and culture on business orientation.

Helmreich, R. L., Beane, W., Lucker, G. W., and Spence, J. T. (1978). Achievement motivation and scientific attainment. Personality and Social Psychology Bulletin, 4(2):222-226.

Ho, V. T. and Astakhova, M. N. (2020). The passion bug: How and when do leaders inspire work passion? Journal of Organizational Behavior, 41(5):424-444.

Hull, C. L. (1943). Principles of behavior, volume 422. Appleton-century-crofts New York. 
Jena, R. (2020). Measuring the impact of business management student's attitude towards entrepreneurship education on entrepreneurial intention: A case study. Computers in Human Behavior, 107:106275.

Jones, D. N. and Paulhus, D. L. (2011). The role of impulsivity in the dark triad of personality. Personality and Individual Differences, 51(5):679-682.

Kerckhoff, A. C. (1976). The status attainment process: socialization or allocation? Social forces, 55(2):368-381.

Lawrence, P. R. and Nohria, N. (2002). Driven: How human nature shapes our choices. Jossey-Bass.

Ly, C. T. M., Vickers, M. H., and Fernandez, S. (2015). Master of business administration (mba) student outcomes in vietnam. Education+ Training.

Mahendra, A. M., Djatmika, E. T., and Hermawan, A. (2017). The effect of entrepreneurship education on entrepreneurial intention mediated by motivation and attitude among management students, state university of malang, indonesia. International Education Studies, 10(9):61-69.

Maqsud, M. (1980). Personality and academic attainment of primary school children. Psychological Reports, 46(3_suppl):1271-1275.

Michalos, A. C. (2008). Education, happiness and wellbeing. Social Indicators Research, 87(3):347366.

Nohria, N., Groysberg, B., and Lee, L. (2008). Employee motivation: A powerful new model. Harvard business review, 86(7/8):78.

Obschonka, M., Moeller, J., and Goethner, M. (2019). Entrepreneurial passion and personality: the case of academic entrepreneurship. Frontiers in psychology, 9:2697.

Ondabu, I. T. (2014). A theory of human motivation: The tirimba grouping theory of motivation. Sop transactions on economic research, 1(1):16-21.

Palalić, R., Ramadani, V., Dilović, A., Dizdarević, A., and Ratten, V. (2017). Entrepreneurial intentions of university students: a case-based study. Journal of Enterprising Communities: People and Places in the Global Economy.
Rabideau, S. T. (2005). Effects of achievement motivation on behavior. Retrieved from.

Ran, X. and Shi, J. (2020). Construction and analysis of chinese college students entrepreneurship motivation model. In The 3rd International Conference on Economy, Management and Entrepreneurship (ICOEME 2020), pages 580-584. Atlantis Press.

Sears, R. R. (1951). A theoretical framework for personality and social behavior. American Psychologist, 6(9):476.

Solesvik, M., Iakovleva, T., and Trifilova, A. (2019). Motivation of female entrepreneurs: a crossnational study. Journal of Small Business and Enterprise Development.

Soomro, B. A., Lakhan, G. R., Mangi, S., and Shah, N. (2020). Predicting entrepreneurial intention among business students of public sector universities of pakistan: an application of the entrepreneurial event model. World Journal of Entrepreneurship, Management and Sustainable Development.

Specht, J., Bleidorn, W., Denissen, J. J., Hennecke, M., Hutteman, R., Kandler, C., Luhmann, M., Orth, U., Reitz, A. K., and Zimmermann, J. (2014). What drives adult personality development? a comparison of theoretical perspectives and empirical evidence. European Journal of Personality, 28(3):216-230.

Spence, K. W. (1956). Behavior theory and conditioning.

Steel, P. and König, C. J. (2006). Integrating theories of motivation. Academy of management review, 31(4):889-913.

Thorne, A. (2000). Personal memory telling and personality development. Personality and Social Psychology Review, 4(1):45-56.

Vallerand, R. J., Houlfort, N., and Fores, J. (2003). Passion at work. Emerging perspectives on values in organizations, pages 175-204.

Watjatrakul, B. (2014). Factors affecting students intentions to study at universities adopting the student-as-customer concept. International Journal of Educational Management. 
Weiner, B. (2010). The development of an attribution-based theory of motivation: A history of ideas. Educational psychologist, 45(1):2836.
Wilson, G. (1997). Pathways to power: Racial differences in the determinants of job authority. Social Problems, 44(1):38-54. 


\section{Appendix}

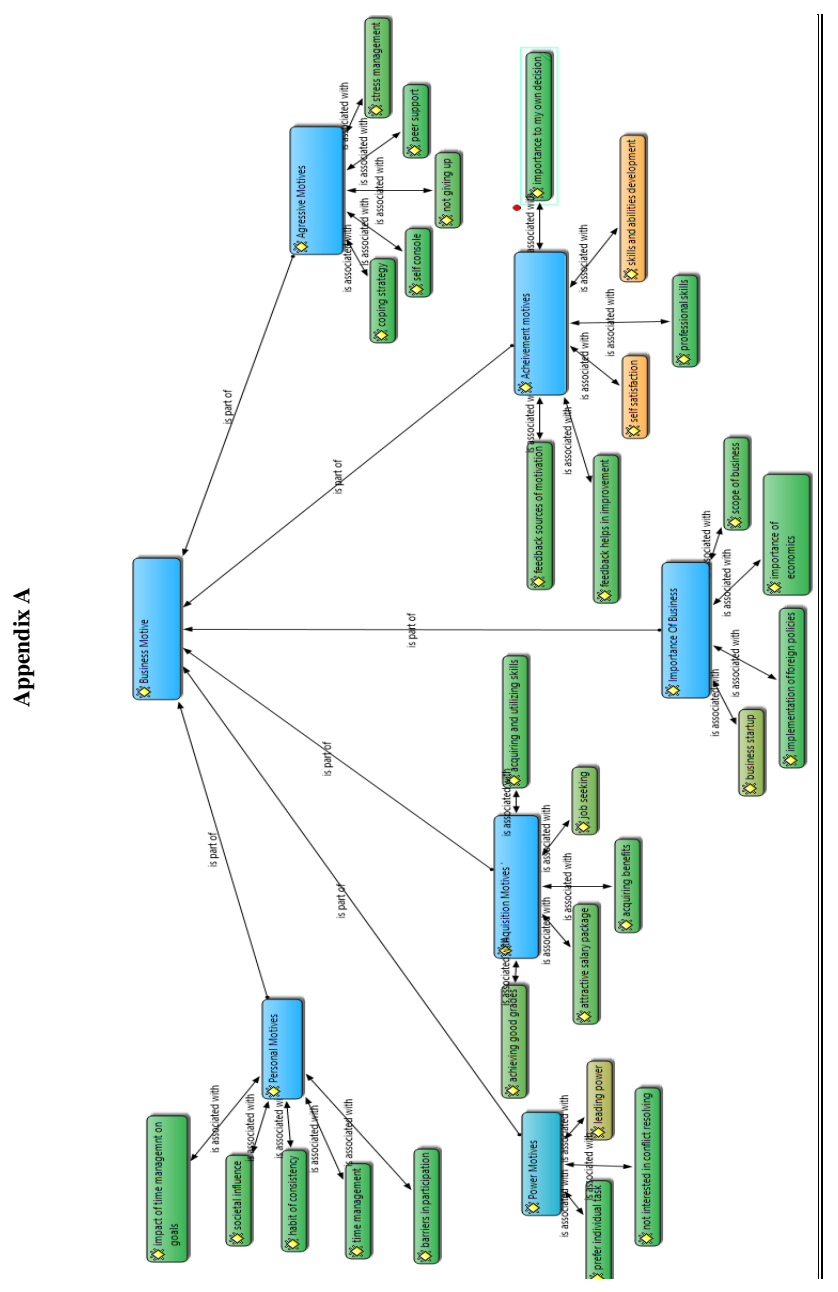




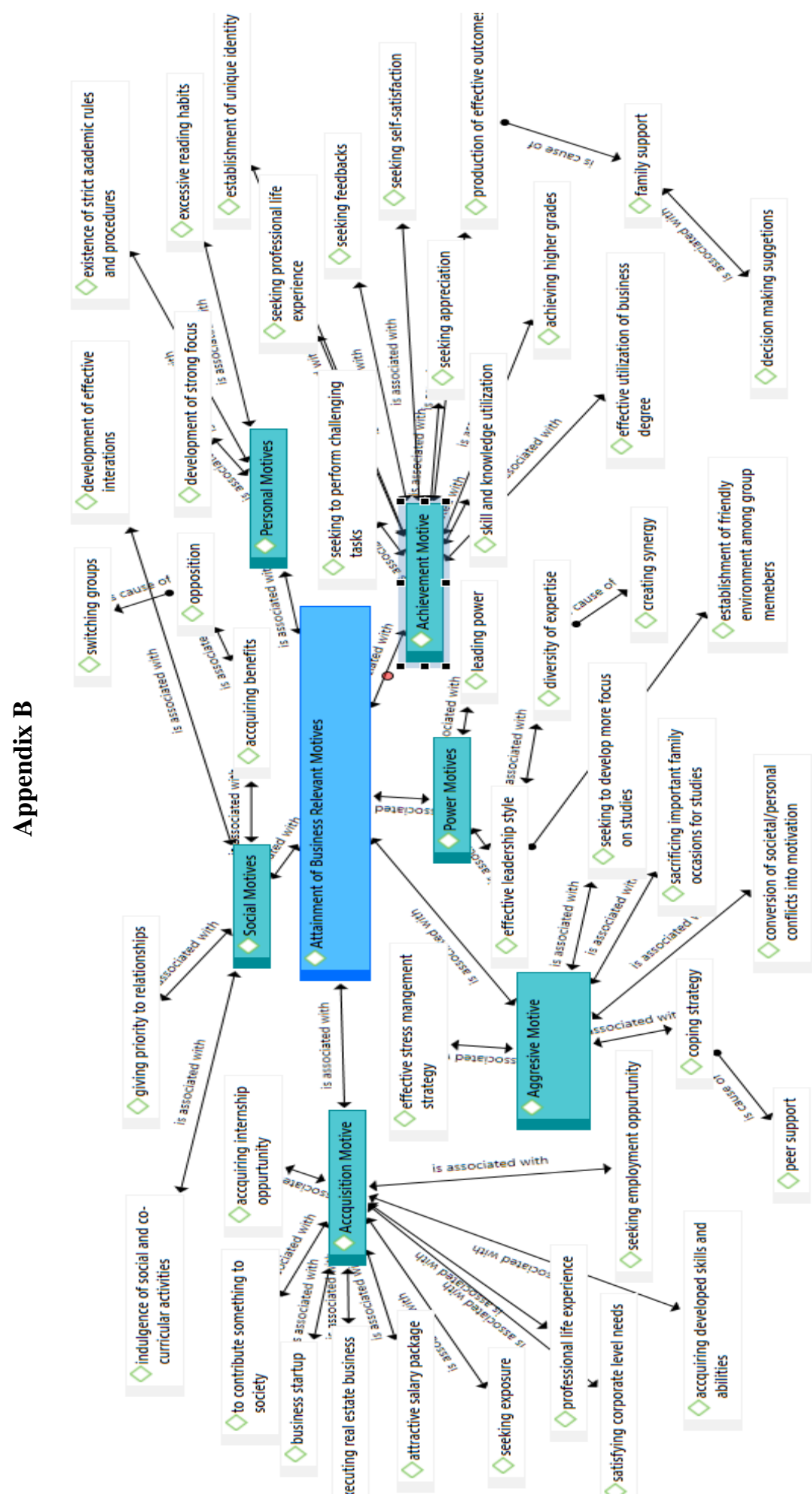

